\title{
APOSTANDO POR JOAN MIRÓ. EL PROTAGONISMO DE LA REVISTA PARNASSUS ENTRE 1932 Y 1941
}

\author{
Javier Pérez Segura \\ Universidad Complutense de Madrid \\ javierpsegura@yahoo.es
}

\begin{abstract}
Este artículo se centra en una de las muchas vías con las que se dio a conocer el arte del español Joan Miró (18931983): la revista Parnassus. Fue publicada entre 1929 y 1941 por una institución llamada College Art Association, y entre 1932 y 1941 dedicó numerosos artículos a explicar el arte de Miró a sus lectores. Se analiza en profundidad el contenido de esos artículos, que ayudan a entender mejor el complejo proceso de recepción en Estados Unidos de movimientos como Dadá y el surrealismo, las diversas opciones de surrealismo y, en especial, el protagonismo que tenía la producción de Miró en todo ese proceso. La estrategia de Parnassus fue, de hecho, muy notable en el triunfo de Miró en Estados Unidos desde ese momento y para el futuro.
\end{abstract}

Palabras clave: Joan Miró; Parnassus; Estados Unidos; Surrealismo; Dadaísmo; Crítica de arte.

\section{BETTING ON JOAN MIRÓ: THE PROMINENT ROLE OF PARNASSUS MAGAZINE BETWEEN} $1932 \& 1941$

This essay focuses on one of the many means by which the art of the Spaniard Joan Miro (1893-1983) came to be known and understood: Parnassus magazine. It was published from 1929 to 1941 by the College Art Association, and between 1932 and 1941 included many articles explaining Miró's art. These articles are analyzed here in depth, as they help to comprehend the complicated reception in the United States of tendencies such as Dada, the several modes of Surrealism and Miro's protagonism in this process. In fact, the strategy used in Parnassus was instrumental for Miró's triumph in the United State from then on.

Key words: Joan Miró; Parnassus; United States; Surrealism; Dada; Art criticism.

En 1911 se creaba la College Art Association of America (en adelante, CAA) con el objetivo de mejorar la formación de los artistas, de los historiadores del arte y, en un plano más amplio, de todo el público estadounidense que pudiera estar interesado en cuestiones artísticas, sin distinción de épocas ni de coordenadas geográficas. Superado el primer siglo de existencia ${ }^{1}$, sus objetivos continúan siendo los mismos y siempre, desde el principio, sus máximos responsables han considerado instrumental el poder contar con una publicación propia desde la que construir, de forma más sopesada y duradera, sus principales líneas de discurso al respecto.

Este artículo se inscribe dentro del Proyecto del Plan Nacional de I+D+i Mineco ref. HAR 2014-53871-P (20152017), "50 años de arte en el Siglo de Plata español (1931-1981)".

${ }^{1}$ Es fundamental la monografía de Ball (2011). 


\section{PARNASSUS}

Puliuhd by the College An Asociation for Asociation member

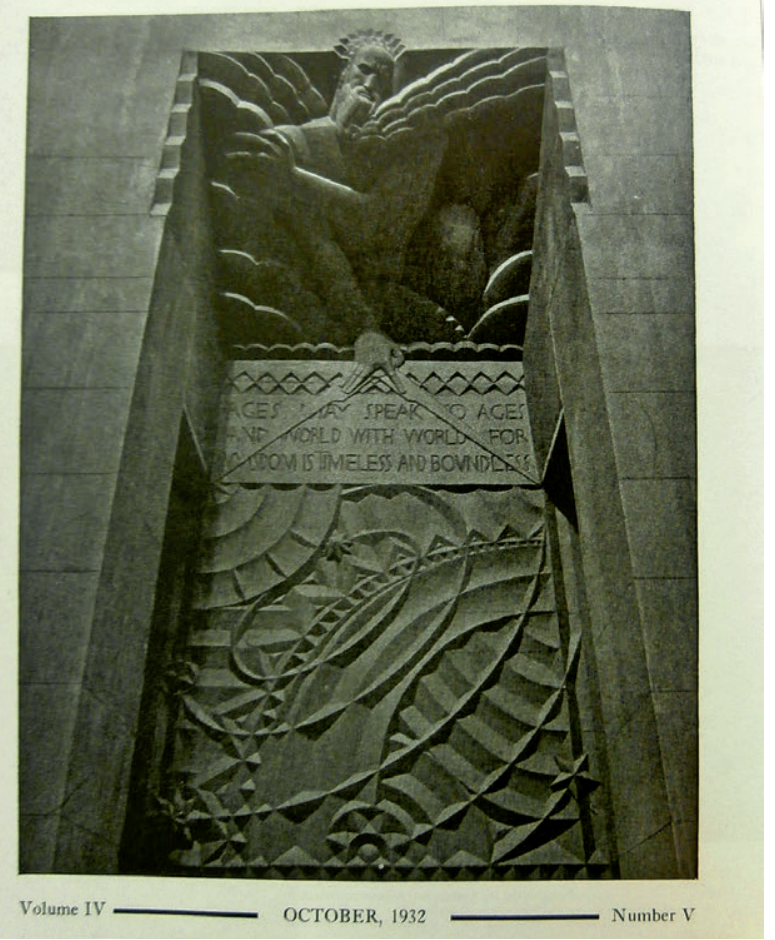

Fig. 1. Portada de la revista Parnassus (octubre de 1932).

Es por ello que ya en enero de 1929 se publicó el primer número de Parnassus, que tuvo una aparición mensual durante el periodo académico universitario, y que mantendría ese título hasta mayo de 1941, cuando lo cambió, primero por College Art Journal (desde noviembre de 1941), y luego por Art Journal (desde otoño de 1960 y hasta la actualidad) ${ }^{2}$.

Parnassus (una revista que sigue siendo casi totalmente desconocida por la historia del arte que se escribe lejos de Estados Unidos) existió, pues, poco más de una década, pero fue una etapa de intensidad asombrosa y, sobre todo, un periodo en el que la CAA se convirtió en agente principal en el complejo proceso de modernización del arte y del gusto artístico que se llevó a cabo en su país.

Así, por ejemplo, en octubre de 1929 la CAA decidió afrontar una atrevida estrategia para difundir eficazmente esas nuevas formas y lenguajes. Puso en marcha una serie de exposiciones itinerantes de arte contemporáneo que recorrerían numerosos centros académicos (tanto colleges como universidades) a lo largo del país. Estamos hablando de muestras grandes, de casi cien obras, cincuenta de ellas óleos y acuarelas, 25 grabados y, en ocasiones, un aporte complementario de esculturas y dibujos. Ese programa de exposiciones ${ }^{3}$ se prolongaría por espacio de ocho años y sería supervisado por un comité de expertos, entre los que destacaba el coleccionista Duncan Phillips, además de Paul Sadar, Walter W. S. Cook ${ }^{4}$, Charles Rufus Morey o el matrimonio formado por A. Phillips y Audrey McMahon, quien además de ser directora ejecutiva fue editora de la revista durante mucho tiempo.

En esos años treinta, la revista -centrada en arte contemporáneo occidental pero también en arte asiático o africano- contaba con secciones dedicadas al mercado del arte, junto a otras donde se reseñaban los libros recién aparecidos y se publicaban abstracts de artículos de revistas especializadas (fig. 1).

Sin embargo, Parnassus y su propuesta editorial no resistieron muchos años. Entre las causas determinantes de su final tendríamos que considerar su evidente enfoque a favor de Europa como único modelo cultural a seguir, siendo ésta una actitud que acabaría chocando con el deseo de una

\footnotetext{
2 A modo de balance de esa trayectoria deben leerse los ensayos de Weiberg (1991) y Singerman (2011).

${ }^{3}$ En las que había habitual presencia de arte español moderno y de vanguardia. Véase los artículos de Fontbona (1998; 2009). También mi libro (Pérez Segura, 2012: 238-239).

${ }^{4}$ Aún poco conocido, sí sabemos que estaba especializado en arte medieval europeo. Es muy ilustrativo, por ejemplo, el artículo de Mata de la Cruz (2011).
} 
parte de la "institución arte" estadounidense de reclamarse, por el contrario, ajena e independiente de esa influencia. Tampoco debemos olvidar su focalización casi exclusiva sobre lo que pasaba artísticamente hablando- en la Costa Este, ninguneando lo que sucedía en otros ámbitos del país; y, más en concreto, sobre lo que se veía en Nueva York (por ejemplo, la agenda de exposiciones en museos y galerías a menudo sólo mencionaba las neoyorquinas); en última instancia, el excesivo protagonismo del matrimonio MacMahon en la toma de decisiones de la revista acabó por ganarles, al parecer, no pocos enemigos.

Como consecuencia de todo lo anterior, en mayo de 1940 se produjo un cambio radical en la dirección de la revista, impulsado por uno de los miembros destacados de CAA, Lester D. Longman, quien apostaría por sustituir el antes comentado "eurocentrismo" por un mayor enfoque sobre los relatos nacionales, así como por centrarse más en cuestiones de educación artística y menos en las concernientes al mercado. Como una gran parte de la publicidad de la revista corría a cargo de las galerías, el proyecto se hundió definitivamente en pocos meses y a mediados de 1941 Parnassus ya no se publicaría más.

Si nos detuviésemos ahora en la cuestión fundamental de qué contenidos habían primado durante esos años treinta en la revista, una de las ideas principales sería que el arte contemporáneo y sus heterogéneas propuestas plásticas ocuparon a menudo un espacio privilegiado en sus páginas.

Como estaba sucediendo en otros medios escritos -no sólo los especializados, también la prensa general- "cubismo", "abstracción" y "surrealismo" eran términos que copaban muchos de los artículos y reseñas de exposición, haciéndose eco de un proceso real que estaba teniendo lugar en la ciudad de Nueva York, donde la década vio cómo quedaba consagrada esa "tradición de la vanguardia" que había empezado en 1913 con la exposición del Armory Show y que en la década de los veinte había tenido instituciones tan dinámicas y eficaces como la Société Anonyme o la Galería de Arte Vivo ${ }^{5}$, liderada por el coleccionista Albert E. Gallatin.

Ya en los años treinta se fundaban y/o echaban a andar con mucha fuerza centros tan prestigiosos como el Museo de Arte Moderno, el Museo Whitney de Arte Americano o la Fundación Solomon R. Guggenheim... y, tanto o más reseñable, el número de galerías superaba el centenar, entre las que destacaban las más combativas en pro de la vanguardia, como Julien Levy o Pierre Matisse. Ambas lideraron la expansión del surrealismo en Estados Unidos y a ellas debe mucho, sobre todo a la segunda, el éxito que tendría el arte del catalán Joan Miró (1893-1983), cuya inagotable capacidad creativa no dejó de estimular los debates teóricos de esa década y las siguientes ${ }^{6}$.

\section{Los distintos perfiles de Miró, bajo la lupa de Parnassus}

En abril de 1932 la revista dedica por primera vez unas líneas al arte de Joan Miró. Era un momento profesional muy interesante si tenemos en cuenta que apenas habían pasado meses desde que se hubieran celebrado las primeras grandes muestras colectivas sobre el surrealismo en Estados Unidos: la más temprana fue la titulada Newer Superrealism, organizada en noviembrediciembre de 1931 en el Wadsworth Atheneum de Hartford, Connecticut ${ }^{7}$; le seguiría, en enero de 1932, la que tuvo lugar en la Galería Julien Levy, en Nueva York, donde ese ismo se presentó "oficialmente", por el enorme eco mediático en la capital del mundo del arte (sin olvidar París, por supuesto) con la exposición titulada Surréalisme.

\footnotetext{
${ }^{5}$ Debe consultarse el libro de Balken (1986) y de la misma autora junto a Lubar (2002).

${ }^{6}$ Para una visión de conjunto sobre este argumento central, véase la monografía de Rose (1982).

7 Zlotsky 1986: 55-57.
} 
En la primera sí había estado presente Miró, con obras clave del periodo como La patata (1928, col. part.) y Sobresalto (1924, Yale University Art Gallery); en la segunda no, sorprendentemente -y algo que, como contaría Julien Levy, siempre consideró un error de bulto por su parte- pero para entonces la visibilidad del arte de Miró quizás necesitaba menos de esa promoción, habida cuenta de que ya había celebrado sus primeras exposiciones individuales en la ciudad de los rascacielos: la primera, en la Galería Valentine (del 20 de octubre al 8 de noviembre de 1930); la segunda, en el mismo lugar, del 28 de diciembre de 1931 al 16 de enero de 1932; la tercera, que sería a su vez la primera organizada en la Galería Pierre Matisse (quien se convertiría en su gran marchante a partir de entonces), estuvo abierta al público durante casi todo el mes de noviembre de 1932.

Es entre medias, como decimos, cuando Parnassus se ocupa de Miró por primera vez. Se trata de un extenso pero sobre todo bastante curioso artículo, escrito por Francis Henry Taylor, entonces Director del Worcester Art Museum, que aprovechaba la publicación del libro de Aldred Scott Warthin sobre iconografía de la muerte en la cultura occidental -The Physician of the Dance of Death. A historical study of the evolution of the Dance of Death mythus in art, 1931- para atacar con saña a la que era vanguardia más polémica entonces, el surrealismo, y, de paso, a la misma idea general de arte vanguardista. El comienzo no puede ser más directo y claro en este sentido:

En lugar de super-civilización nos ofrecen ahora superrealismo, una especie de extracto de hígado freudiano que contrarreste la perniciosa anemia que sufre la Escuela de Paris como enfermedad mortal. Nos han suministrado una serie de exposiciones intravenosas que sólo han tenido éxito para aumentar la presión de la sangre de los críticos mientras el paciente se sigue hundiendo. Es, además, una crisis para los galeristas ya que si, como Joan Miró ha dicho, uno de los principales objetivos de los surrealistas es 'assassiner la peinture' (sic) la alimentación manual será rechazada de todos modos ${ }^{8}$.

Resulta muy interesante que el de Miró sea el único apellido asociado entonces al surrealismo que aparece en el artículo, así como que la única ilustración de arte contemporáneo que hay -las demás reproducciones pertenecen a obras de arte de medieval y moderno- sea también una obra suya, Maternidad (1924, Galería Nacional de Arte Moderno de Escocia), que comenta explícitamente haber tomado de la reproducción del libro Surreálisme de André Breton. En realidad se refiere a Le Surréalisme et la Peinture (1928), un texto con muchas ilustraciones de otros artistas (Picasso, Braque, De Chirico, Picabia, Ernst, Man Ray, Masson, Tanguy y Arp), también suyas ${ }^{9}$, claro, así como una valoración -que en realidad acaba ofreciéndose muy ambigua- sobre el curso del arte del catalán, al que avisa de los peligros de confiarlo todo a la imaginación como fin y no exclusivamente como medio.

La única explicación a todo este "epitomizar el surrealismo en Miró" -además de que así lo afirmaba Breton precisamente en ese libro ${ }^{10}$ - podría ser que, a raíz de su enorme escándalo en 1929 con la presentación del cuadro Perro ladrando a la luna (1926, Museo de Arte de Filadelfia) en la Galería de Arte Vivo, una gran parte de la prensa neoyorquina le consideró el genuino líder

\footnotetext{
8 Taylor 1932: 4.

9 En concreto, Tierra labrada (1923-1924, Museo Solomon R. Guggenheim), Paisaje catalán (1923-1924, Museo de Arte Moderno, Nueva York), La familia (1924), Maternidad (1924), El circo (1927, Museo de Ixelles), Mano que atrapa un pájaro (1926, col. part.), Perro ladrando a la luna (1926, Museo de Arte Moderno, Filadelfia) y Desnudo (1926, Museo de Arte Moderno, Filadelfia).

10 "Quizás sólo existe en Miró un deseo de abandonarse para pintar, y sólo para pintar [...] en ese automatismo puro al que, por mi parte, nunca he dejado de apelar pero cuyo valor y razón profundas me temo que Miró por sí mismo haya verificado demasiado someramente. Es quizás por eso que puede pasar como el más surrealista de todos nosotros" (Breton, 1928: 62).
} 
del movimiento surrealista. Sin embargo, los ataques de entonces tenían que ver con el aspecto infantil o la deformación figurativa pero no con el término "descomposición", que titula el artículo y que uno esperaría más asociado a alguien como Salvador Dalí -cuya obra La persistencia de la memoria (1931), había desconcertado tanto en la exposición colectiva del surrealismo en la Galería Julien Levy, celebrada en enero de 1932- o a sus colegas Yves Tanguy o Max Ernst ${ }^{11}$, ni con los intentos de Taylor de definir el surrealismo con otro término no menos peyorativo, el de "lo macabro", que le permitía poner en pie una muy cuestionable teoría -con exhaustivo recorrido histórico desde la Edad Media y su profusa iconografía, en el que cita a Huizinga, Mâle o al propio Warthin, del que ya hemos hablado-según la cual el surrealismo sería la más acabada forma actual de toda esa inclinación morbosa, asunto que de nuevo guardaría más relación con la propuesta daliniana que con la mironiana:

Con el Dadaísmo llegó la trágica confesión final de que el artista no tenía nada más que decir [...] debería superar el realismo y mostrar al mundo el superrealismo del espíritu, el misterio del subconsciente, traduciendo los objetos ordinarios en formas extrañas, horribles y sentimentales [...] el resultado del surrealismo ha sido arrastrar al pintor cada vez más a la especulación de su pesimismo privado [...] el surrealismo es una forma de sadismo intelectual que intenta sublimarse a través de las doctrinas freudianas y de los símbolos oníricos.

Es, sin embargo, esta curiosidad por la putrefacción, por los estadios agusanados de la descomposición, lo que supone la mejor promesa para el futuro de la pintura [...] El cuerpo intelectual estéril del movimiento moderno está a punto de yacer en una tumba hecha por él mismo [...] Posiblemente a partir del cadáver del experimento que ha estado pudriéndose cerca de treinta años, algunos gusanos de esperanza harán crecer un organismo viril que puede transmitir el germen del arte creativo a las generaciones futuras ${ }^{12}$.

A comienzos de 1934, y con motivo de la segunda individual de Miró en Pierre Matisse, celebrada del 29 de noviembre de 1933 al 18 de enero de 1934, Rita Wellman, crítica de arte y habitual colaboradora en la revista, escribe una larga reseña de exposiciones. Después de defender la vitalidad y originalidad de la pintura regionalista americana frente a lo que argumentaba como agotamiento de la que a veces era llamada a veces la Escuela de París -denominación que en ocasiones como ésta era sinónimo de "arte contemporáneo europeo"-, Wellman saludaba la potente presentación de las obras recientes del artista catalán:

Dejemos a los europeos dar vueltas sobre la cuarta dimensión y el subconsciente. Su obra, lo sabemos cuando la analizamos, es estridente y falsa. Pero de vez en cuando llega un europeo y sobresalta nuestra complaciente opinión sobre nosotros. Es, por ejemplo, la obra de Joan Miró que ahora se ve en la Galería Pierre Matisse. Tiene el tipo de alegría que me temo no podemos encontrar en una vieja granja de Kansas, y un sentido del color que tampoco podemos obtener de allí. Los tempranos manuscritos religiosos de la Colección Morgan revelan dónde toma este español su color y sus audaces yuxtaposiciones. Incluso aquéllos que piden representación no pueden evitar quedar encantados con estos colores. Aquí hay justificación para 'el ojo inocente'. Un niño podría entender estas composiciones. Y el niño que existe en el adulto se despierta de nuevo cuando las ve. En la exposición de Matisse hay nueve pinturas con figuras, y diez abstracciones etiquetadas simplemente como 'Composiciones'.

\footnotetext{
${ }^{11}$ Por supuesto no me olvido de Luis Buñuel y sus películas de 1929, Un perro andaluz, y 1930, La edad de oro, cuyos estrenos parisinos debieron tener algún tipo de eco en la prensa americana, si bien Un perro andaluz fue proyectada por primera vez en Estados Unidos medio año después de este artículo en Parnassus, en concreto el 17 de noviembre de 1932 en la Galería Julien Levy.

12 Taylor, 1932: 39.
} 
Las obras con las figuras más pequeñas, pintadas sobre madera, tienen las yuxtaposiciones de color crudo de la antigua Cataluña que resultan tan frescas y estimulantes como aquéllas de los viejos manuscritos. Pero son las grandes Composiciones las que captan la atención. O, mejor, no lo hacen. Uno se siente a gusto con estas cosas. Crean una atmósfera. Sus azules te relajan como el cielo mediterráneo. Sus ritmos te comunican sus vibraciones sin intrusión. Son impersonales y ordenadas, como el arte chino. En otras palabras, son decoración, y hechas por un pintor que sabe cómo $\operatorname{pintar}^{13}$.

\section{6: Miró ¿dadaísta? ¿surrealista? ¿o nada de eso?}

Hay que esperar a ese año 1936 para encontrar nuevas aproximaciones al arte mironiano desde la revista que estamos analizando. La causa principal es, cómo no, la celebración de sendas exposiciones de carácter casi enciclopédico que organizó ese año el Museo de Arte Moderno. En marzo, Cubismo, arte abstracto; en diciembre, Arte fantástico, dadá, surrealismo. Aunque el catalán estuvo presente en ambas muestras, fue en la segunda donde triunfó plenamente, en gran parte porque vino a ratificar una idea que llevaba un tiempo fraguándose -gracias, entre otros, al reconocido crítico de arte J. J. Sweeney ${ }^{14}$ - como era la de que, en realidad, no había sólo un surrealismo sino dos caminos distintos, de hecho muy distintos, encarnados en Salvador Dalí y Joan Miró respectivamente.

Desde Parnassus, el historiador del arte John G. Frey escribe el artículo más clarividente de los que aparecieron allí sobre nuestro artista. Se titula "Miró y los surrealistas" y comienza estableciendo con claridad esa división entre los que acabará definiendo como "pintores-poetas" y "poetas-pintores":

Los cuadros de los surrealistas serán clasificados, en bruto, en dos clases. Los cuadros del primer tipo pueden ser llamados 'poemas para ser colgados en la pared', e incluyen obras de Salvador Dalí, Pierre Roy y, quizás, Yves Tanguy. Se caracteriza por un 'modo literario'; la poesía de la imagen surge de lo que representa [...] La técnica empleada es puramente literal, una transcripción exacta de una alucinación personal [...] en oposición a este tipo de pintura, cuya eficacia deriva de lo que es representado [...] podemos apuntar la obra de otro grupo de surrealistas que muestran, en una forma en que no lo hacen Dalí ni Roy, los verdaderos instintos de pintor. Yo llamaría 'lirismo plástico' a este segundo tipo de surrealismo. Aquí el flujo creativo espontáneo de la imaginación en el proceso de la pintura automática se manifiesta, no en una serie de imágenes sino en el crecimiento orgánico de una concepción plástica. La distinción entre ambos tipos surge de una diferencia en los materiales con los que la imaginación trabaja habitualmente. Es la distinción entre la imaginación de un poeta, como Dalí, y la imaginación de un pintor, como Arp. El surrealismo admite ambos, ambos pueden representar por igual el 'puro automatismo psíquico' y el 'descontrolado juego de la imaginación', pero la pintura surrealista se divide, sobre esta base, en poetaspintores y pintores-poetas $[\ldots]^{15}$.

Después realiza la encomiable tarea de recorrer la trayectoria previa de Miró para intentar establecer algunos principios con los que el público y el lector pudieran comprender su arte. En general, hoy el estado de la cuestión sobre esos años ha cambiado bastante, pero las opiniones que

\footnotetext{
13 Wellman, 1934: 12.

${ }^{14}$ Sweeney, 1935: 360 apostaba sin ambages por Miró, cuya autenticidad era fruto de sus raíces culturales catalanas, frente al que pensaba artificio del lenguaje daliniano.

${ }^{15}$ Frey, 1936a: 13.
} 
arriesgaba Frey entonces conservan, en ocasiones, el hallazgo de la intuición y, en consecuencia, siguen siendo clarificadoras sobre la fortuna crítica del artista:

La pintura de Miró manifiesta una progresión, o una serie de progresiones, desde el poeta-pintor al pintor-poeta. En 1923-1924 la imaginación de Miró funcionaba en términos de imágenes que eran descritas en pintura, en símbolos, si se quiere, pero que eran del tipo psicoanalítico [...] Es un periodo de imitaciones de objetos, el placer es el del reconocimiento. La poesía de Miró, en ese momento, consiste en las peculiares combinaciones de imágenes que caen desde el subconsciente en el medio de la pintura automática, el fortuito encuentro sobre un plano inadecuado de un número de realidades hostiles. Las pinturas de 1923-1924 son difusas, les falta una organización central; el pintor es absorbido por los detalles diminutos; es una pintura de 'pasajes interesantes'; el ojo no puede enfocar el conjunto.

Durante los siguientes cinco años los cuadros de Miró se purificaron cada vez más. Los lienzos estaban menos poblados; los objetos descritos eran cada vez más simplificados, reducidos a formas esenciales; se convirtieron finalmente en meros símbolos caligráficos; el color se hizo más intenso. Las áreas de color, más fuertemente opuestas; aumentó la tensión de las líneas. El cambio fue claramente puesto de relieve en Le Surréalisme et la peinture, de André Breton [...] Hacia 1927, los cuadros de Miró se habían convertido en abstracciones casi completas ${ }^{16}$.

Se refiere después a la crisis que siguió en su producción y a ese cierto regreso a la figuración, al viaje a Holanda y a cómo los Interiores holandeses le recordaban mucho a los Paisajes catalanes del año 1923; de cómo introdujo el collage y la pintura sobre madera en los primeros años treinta y de cómo en las obras de 1933 se habría producido una nueva inspiración en sus etapas previas. Advierte, eso sí, que "la carrera de Miró no debe ser entendida como una serie de repeticiones sin alma, sino como una espiral ascendente en la que el pintor continúa regresando a ciertas constantes en su carácter, recuperando cada vez una sensibilidad enriquecida y una experiencia más profunda. En los lienzos de 1933 usa el collage de un modo que Dalí describiría como 'interpretación paranoica'. El pintor pega una fotografía sobre el lienzo y de inmediato, sin dudar ni reflexionar, empieza a pintar a su lado y alrededor y por encima, cualquier cosa que evoque desde su subconsciente. El resultado, lo que Dalí llama 'imágenes múltiples de la paranoia', será un reemplazo de la obra original bien por algún equivalente plástico bien por una serie de metáforas visuales, o por una combinación de ambas".

Aprecia una diferencia importante, por el contrario, a partir de las obras realizadas en $1934^{17}$ (y que habían sido presentadas en una nueva individual en la Galería Pierre Matisse, del 10 de enero al 9 de febrero de 1935), como la sustitución de los colores puros del año 1932 por una gama de naranjas y rojos ácidos, el cambio de escala en las figuras, hacia un tamaño cada vez mayor; el final del lirismo y, en su lugar, un modo de hacer que "es más histérico, más exasperado, más violento, y ese cambio ha necesitado cambios más radicales y nuevos en el color y en el trazo". En suma, una tendencia hacia un mayor simbolismo -dominado por la iconografía de tipo genital y sexual- frente al automatismo precedente.

Es interesante notar que los cuadros de Miró que son saludados con grandes aclamaciones por los críticos (incluido yo mismo en este artículo) son aquéllos de un tipo casi abstracto, de los que se habla de la misma manera que se hacía con los primeros cuadros cubistas o de los cuadros puristas

\footnotetext{
${ }^{16}$ Frey, 1936a: 14.

${ }^{17}$ De hecho, ese nuevo lenguaje que defiende Frey en este artículo queda reforzado por la selección de las dos únicas reproducciones de obra que lo acompañan: Sobresalto (1924), cuyo pie de foto indica que es una de las obras que iban a estar en la exposición de la CAA en diciembre de 1936, titulada Nuevas formas en arte; y la acuarela Lluvia (1935), cortesía de la Galería Pierre Matisse.
} 
de Ozenfant y Mondrian. La última actitud colocaría a Miró en la posición anómala de quien está preocupado con la ‘composición', la 'forma significante' o los 'valores plásticos', en contradicción con la rígida definición del surrealismo como 'libre de toda preocupación estética o moral' [...].

A la vista del principio surrealista, los reiterados regresos de Miró a la representación son indicativos perfectamente naturales de la continua operación de su pensamiento en el mundo de la acción, la esfera moral [...] Al mismo tiempo, la tendencia a la abstracción tiene que ser vista como un resultado natural de la sensibilidad hacia la línea y el color.

[...] Cuando la tendencia selectiva es inconsciente, e incluso puramente espontánea, como en el caso de la pintura automática de Miró, está siempre en peligro de ser relegada por otras demandas más inmediatas.

[...] En consecuencia, encontramos en la pintura de Miró cambios repentinos que serían inexplicables de otra forma, cambios desde la abstracción virtual hasta el tipo de agudo realismo-procedente-del-mundo-de-los-sueños que encontramos en los cuadros de Dalí. La relación entre Dalí y Miró puede ser entendida de esta forma: si Dalí es el Courbet del mundo onírico, Miró es su Greco, o mejor, su Picasso.

Como sabemos, esta contraposición entre las poéticas daliniana y mironiana quedaría definitivamente consolidada -si no lo estaba ya antes- a partir de la exposición Arte fantástico, dadá, surrealismo, que estaba a punto de inaugurarse en diciembre de ese mismo año 1936 en el Museo de Arte Moderno de Nueva York ${ }^{18}$.

Es, precisamente, con motivo de esta muestra cuando John G. Frey escribiría un nuevo artículo sobre surrealismo, en este caso con la pretensión de marcar diferencias entre aquél y su ilustre predecesor, Dadá, al que consideraba estéril en su actitud autodestructiva, como por otra parte pensaba entonces la gran mayoría de la crítica estadounidense: "Es obvio que el perfecto dadaísta es un rara avis porque su total nihilismo, el absoluto rechazo de todo, deja una sola salida, el suicidio [...] el surrealismo tiende a una concreción cada vez mayor, a la comprensión real de la imagen del sueño o de lo irracional en la realidad, y finalmente a la acción de imágenes oníricas simbólicas para determinar o alterar el flujo irracional del pensamiento $[\ldots]^{p 19}$

Respecto a Joan Miró - cuya obra Muchacha saltando a la comba (1935), un gouache que había visto en su exposición individual de noviembre a diciembre de 1936 ilustra el artículo, junto a una de Max Ernst y otra de Dalí- Frey mantiene la división de las prácticas surrealistas en figurativas y líricas: "Si debemos apreciar a Ernst por descubrir esos placeres de lo misterioso, de lo maravilloso, que iban a ser más tarde explotados ampliamente por Tanguy y Roy y Dalí, entonces también debemos agradecer a Arp la inspiración que ofreció en el campo de la creación plástica espontánea y del lirismo plástico tan maravillosamente pleno en los cuadros de Miró" ${ }^{20}$.

Esta interpretación crítica de Miró con algunos dadaístas hizo que durante el periodo que analizamos se le llegara a identificar con uno de ellos e incluso como uno de sus líderes ${ }^{21}$.

La segunda parte del artículo de Frey se centra en comentar las diferencias aportadas por el surrealismo respecto a Dadá, sobre todo una, la de un cambio de actitud (de pasividad a activismo),

${ }^{18}$ Y que ya sería algo superado en la doble muestra monográfica que les dedicara a ambos el mismo museo cinco años más tarde, a fines de 1941, cuando -en nuestra opinión- sobraba todo debate por la creciente falta de interés de crítica y público por la propuesta daliniana frente a la siempre inspiradora originalidad de la producción de Miró.

${ }^{19}$ Frey, 1936b: 12.

${ }^{20}$ Frey, 1936b: 13.

${ }^{21}$ Por ejemplo, en el artículo anónimo que aparece en Ken (Nueva York, 27-4-1939) y en el que se puede leer: "El dadaísmo nació en el año 1920. Su padre fue Joan Miró, ahora una luz que guía la escuela surrealista. Miró posa aquí con una de sus creaciones dadá, comparándola con la acuarela hecha por su pequeña hija”. 
que se habría concretado en una vuelta a los objetos. En realidad lo que hace el autor es repetir algunas ideas ya expuestas en ese artículo dedicado a Miró en octubre del que hemos hablado antes. Por ejemplo, la valoración positiva del collage en todo ese proceso emprendido por el surrealismo, o el protagonismo del método paranoico crítico teorizado y puesto en práctica extensivamente por Dalí desde hacía pocos años. En ese predominio del objeto - encontrado, modificado o incluso creado intencionadamente por los surrealistas- encuentra Frey la manifestación más válida de esa tendencia, llegando incluso a dudar de la supervivencia de la pintura, al menos entendida en términos tradicionales. A este respecto, y si bien es verdad que el envío de Miró en esa exposición del Museo de Arte Moderno eran abrumadoramente pictórico y bidimensional, también presentaba la obra $\mathrm{Ob}$ jeto poético. Loro disecado sobre madera (1936, Museo de Arte Moderno de Nueva York), en sintonía con otros objetos allí presentes, como los de Marcel Duchamp, Max Ernst, Meret Oppenheim o Man Ray, muy en línea con la celebración reciente de algunas exposiciones surrealistas en Europa, como la de la Galería Charles Ratton de París en primavera de ese mismo año.

\section{Nuevas perspectivas sobre su arte}

La presencia de Miró en la revista continuó en los meses posteriores. Por ejemplo, Emily Genauer (importante crítica de arte, habitual de las páginas del New York World y New York Herald Tribune) comenta en un artículo el creciente interés que estaba teniendo la pintura mural en Occidente, y utiliza como ejemplo lo que estaba sucediendo en la Exposición Internacional de París (1937). En el recorrido que hace por los diversos pabellones, llega al de la República española y comenta: "En el edificio español está el soberbio panel de Picasso de cuarenta pies, una abstracción en negros, grises y blancos, dibujando con el más dramático efecto los horrores de la guerra civil en España. En el mismo edificio hay un gran mural decorativo por Joan Miró, ejecutado sobre yute, un panel que no tiene más historia ni propósito que el puramente decorativo"22.

Evidentemente, Genauer demostraba un desconcertante y total desconocimiento de que las intenciones ideológicas del Guernica de Picasso eran las mismas que las de El segador (Campesino catalán en revolución) y el que atribuyese a la que fue una de las obras maestras del periodo y de la trayectoria de Miró la condición exclusiva de algo "puramente decorativo" indica, pensamos, que aún -y pese a todo lo conseguido- existían muchas resistencias a su arte en Estados Unidos. Y si sucedía así en Nueva York, donde más o menos Miró exponía con regularidad desde hacía diez años, mucho más en lugares como Pittsburgh, cuyas Internacionales ${ }^{23}$ sólo aceptaron una obra suya (Paisaje animado, 1935) en 1938. Fue entonces cuando Parnassus encarga al crítico de arte J. J. Sweeney que valore esa edición, en la que él destacará principalmente esa presentación de Miró (fig. 2), además del tono general muy conservador en cuanto a los artistas que habían sido seleccionados y los que habían obtenido algún premio:

Tras Francia, España, con Picasso y Miró, es probablemente más eficazmente representada desde el punto de vista de un comentario vívido del lenguaje pictórico tan cambiante. Es verdad que ni el Paisaje animado de Joan Miró ni la Mandolina y jarrón con flores (1929) de Picasso son buenos ejemplos de la obra de ambos artistas durante esos años, y mucho menos de sus producciones más recientes.

\footnotetext{
${ }^{22}$ Genauer, 1937: 9.

${ }^{23}$ Se llamaban así a los certámenes anuales de pintura occidental que venía celebrando cada año, desde 1896, el Instituto Carnegie, en Pittsburgh, Pensilvania.

${ }^{24}$ Sweeney, 1938: 17.
} 


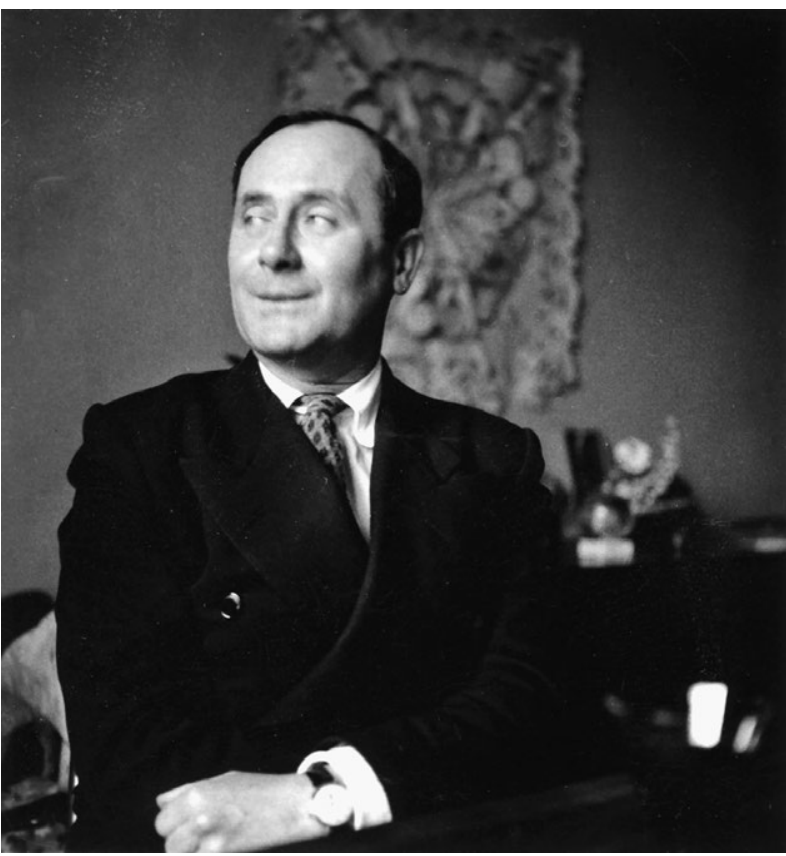

Fig. 2. Joan Miró fotografiado por Margaret Palmer, del Instituto Carnegie, ca. 1938-1939.

Courtesy of the Carnegie Museum of Art. Carnegie Institute.

Sin embargo, los marrones, rojos, blancos y negros del paisaje onírico de Miró constituyen uno de las mejores organizaciones de color individuales de la exposición. Y la disposición rítmica de sus formas lineales distorsionadas sugiere una libertad que quizás ningún otro pintor en toda la exposición se ha atrevido a ensayar ${ }^{24}$.

Realmente, y en nuestra opinión, todo este proceso de creciente aceptación del arte de Miró por parte de la crítica especializada durante los años treinta sólo tendría su culminación a comienzos de la década siguiente. En 1941 una importante individual en la Galería Pierre Matisse se inauguraba del 4 al 29 de marzo. Fueron quince cuadros y diez dibujos y gouaches ${ }^{25}$ que, de nuevo, llamaron la atención del equipo redactor de Parnassus, que publicó una reseña a cargo de Milton Brown, profesor de la Universidad de Nueva York ${ }^{26}$. Lo primero que sorprende de este nuevo ensayo es que Miró es posicionado junto a dos pintores abstrac$\operatorname{tos}^{27}$ que también acababan de exponer en la ciudad, Wassily Kandinsky y Lionel Feininger ${ }^{28}$, aunque se acabara decantando por la imaginación desbordante del catalán:

En Miró (Galería Pierre Matisse) y Kandinsky (Galería Nierendorf) el nexo entre arte y naturaleza está cortado. El tema, si es que existe, es reminiscente y fragmentario más que explícito. Incluso trabajando en términos abstractos, ambos se expresan como personalidades distintas, tan precisamente definidas como si hubieran anotado alguna relación, natural o humana, inteligible. Evidentemente hay más de un modo de ser ininteligible. Miró es sin duda el chico malo del arte moderno -inteligente, impredecible, malicioso, vigoroso, pleno de energía e imaginación. Carece por com-

${ }^{25}$ Uno de ellos, Personajes magnetizados por las estrellas (ca. 1940-1941) ilustraba a página completa ese texto.

${ }^{26}$ Milton W. Brown (1911-1998) es una de las figuras clave en la historia del arte contemporáneo en Estados Unidos. Después de formarse junto a profesores como Erwin Panofsky, Walter Friedlander o Meyer Schapiro, obtuvo el doctorado en el Instituto de Bellas Artes de Nueva York y trabajó (en 1938-1939) en el Museo de Arte Fogg, de la Universidad de Harvard.

${ }^{27}$ En este sentido hay que distinguir con claridad entre la imagen que una parte de la crítica americana había construido alrededor de su arte, y que le insertaba en una genérica tendencia simplificadora formal, y lo que el propio artista afirmaba, como su alejamiento explícito de grupos abstractos como el parisino Abstraction-Création.

${ }^{28}$ Y que pertenecían a la generación gloriosa de la vanguardia histórica. Desde el comienzo de la segunda guerra mundial hubo un interés muy evidente por conocer cómo estaban reaccionando al conflicto los seniors del arte contemporáneo europeo, como constatan numerosos artículos de la época. Mientras Kandinsky permaneció en París hasta su fallecimiento en 1944, Feininger fue uno de los primeros artistas exiliados alemanes en llegar a Nueva York, en los últimos años treinta. 
pleto del acercamiento minucioso y casi arqueológico de Klee a la mente infantil y, en su lugar, podríamos decir que se ha convertido en esa mente infantil. Sin embargo, no ha perdido nada de su sofisticación como artista en el proceso de convertirse en niño. Su gusto sigue permaneciendo estéticamente impecable. Es sorprendente cómo puede organizar su material esencialmente ilógico en una composición ilógica y conseguir una unidad inquebrantable. En sus manos el arte se ha convertido en un producto de prestidigitación, un ejercicio 'sin sentido' a través del cual la aguda perfección de su ejecución se convierte en un logro artístico soberbio.

Kandinsky difiere de Miró y de los demás grandes maestros de la Escuela de París en su falta de capacidad inventiva brillante [...] A pesar del completo repertorio de la amplia paleta de Kandinsky, permanece siempre fríamente intelectual, y nunca consigue la riqueza e intensidad que Miró puede evocar con unos pocos simples colores. El único ingrediente del que carece Kandinsky y que le hace difícilmente apreciable es el gusto y es precisamente lo que Miró, ni siquiera en su obscenidad, nunca ha perdido ${ }^{29}$.

A finales de ese año, 1941, el Museo de Arte Moderno de Nueva York le dedicaba la primera exposición individual, con un amplio recorrido de 85 obras fechadas entre 1918 y 1939, y que le consagraría definitivamente entre las nuevas generaciones. El texto principal de ese catálogo, escrito por el comisario y gran amigo del artista catalán, J. J. Sweeney, sigue siendo considerado esencial para definir algunas de las claves de su arte y para proyectar su influencia entre los críticos $\mathrm{y}$ artistas estadounidenses a partir de ese momento ${ }^{30}$.

Como hemos visto, el interés que despertó la obra de Joan Miró en una revista tan destacada como Parnassus indica con claridad el grado de conocimiento cada vez más profundo que existía sobre su arte, y sobre el arte contemporáneo en general, así como la capacidad de generar opinión que tenía la publicación.

Aunque las aproximaciones a su obra durante esos años treinta fueron muy diversas (desde la teoría de arte en general hasta su aplicación concreta en ciertas obras, como la del pabellón español en la exposición de París de 1937, pasando por la comparación con miembros del surrealismo internacional o con coetáneos de otras vanguardias) en Parnassus predominó el tono de admiración $y$, debido a su enorme prestigio entonces, hay que empezar a considerar dicha revista como uno de los factores destacados en el proceso de consagración crítica del arte de Miró.

\section{BIBLIOGRAFÍA}

Balken, Debra B. (1986): Albert Eugene Gallatin and his circle, Miami, Universidad.

Balken, Debra B. / Lubar, Robert S. (2002): The Park Avenue Cubists: Gallatin, Morris, Frelinghuysen and Shaw, Nueva York, Universidad y Galería de Arte Grey.

Ball, Susan (2011): The Eye, the Hand, the Mind. 100 years of the College Art Association, Nueva York, College Art Association and Rutgers U. P.

Breton, André (1928): Le Surréalisme et la Peinture, París, NRF.

Brown, Milton (1941): "Exhibitions: New York". En: Parnassus, 13, 4, Nueva York, pp. 154-156+158.

Fontbona, Francesc (1998): "La Exposición Internacional de la College Art Association en Nueva York". En: Goya. Revista de arte, 262, pp. 13-16.

Fontbona, Francesc (2009): "Notes sobre la difusió de l'art català als Estats Units”. En: Seminari Comerç, Exportació, Falsificació d'objectes d'art, e-artDocuments, 1, Barcelona, Universitat. http://www.raco.cat/index-php/eart/article/view/147791 [Consulta: 13-01-2015].

\footnotetext{
${ }^{29}$ Brown, 1941: 154.

${ }^{30}$ Pérez Segura, 2012: 251-254.
} 
Frey, John G. (1936a): "Miró and the Surrealists”. En: Parnassus, 8, 5, Nueva York, pp. 13-15.

Frey, John G. (1936b): "Dada and Surrealism”. En: Parnassus, 8, 7, Nueva York, pp. 12-15.

Genauer, Emily (1937): “All-star Casts”. En: Parnassus, 9, 5, Nueva York, pp. 9-12.

Lázaro Docio, Jesús (2010): El secreto creador de Salvador Dalí. El método paranoico-crítico (1927-1937), Madrid, Eutelequia.

Le Surréalisme et l'objet (2013): París, Centre Georges Pompidou.

Levy, Julien (2003): Memoir of and art gallery, Nueva York, MFA.

Lubar, Robert (1992): "Miró, Dalí and Their American Critics in 1941”. En: Actes dels IV Jornades d'Estudis CatalanoAmericans, Barcelona, Generalitat de Catalunya, pp. 27-32.

Lubar, Robert (2005): "Salvador Dalí in America: The Rise and Fall of an Arch-Surrealist". En: Surrealism U.S.A., Nueva York, National Academy Museum and Hatje Cantz Publishers, pp. 20-29.

Mata de la Cruz, Sofía (2011): "La correspondencia entre Walter W. S. Cook y Joan Serra Vilaró 1923-1954. La mirada estadounidense sobre la pintura románica catalana”. En: Pérez Mulet, Fernando / Socias, Inmaculada (eds.), La dispersión de objetos de arte fuera de España en los siglos XIX y XX, Barcelona-Cádiz, Universidad, pp.191-216.

Pérez Segura, Javier (2012): Scandal \& Success. Picasso, Dali y Miró en Estados Unidos (El Instituto Carnegie y otros relatos americanos), Madrid, Eutelequia.

Pierre Matisse and his artists (2002): Nueva York, Pierpoint Morgan Gallery.

Pierre Matisse, passeur passionné. Un marchand d'art et ses artistes (2005): Nueva York, Fundación Mona Bismarck. Rose, Barbara (1982): Miró in America, Houston, Museo de Bellas Artes.

Russell, John (1999): Matisse, father and son, Nueva York, Harry N. Abrams.

Schaffner, Ingrid y Jacobs, Lisa (eds.) (1998): Julien Levy: portrait of an art gallery, Cambridge, The MIT Press.

Singerman, Howard (2011): “Art Journal at Fifty". En: Art Journal, Nueva York, $<\mathrm{http}: / /$ www.artjournal.collegeart.org/7p=65> [13-01-2015].

Sweeney, James Johnson (1935): "Miró and Dalí”. En The New Republic, Nueva York, 81, p. 360.

Sweeney, James Johnson (1938): “Carnegie International 1938”. En: Parnassus, 10, 6, Nueva York, pp. 13-18.

Taylor, Francis H. (1932): “The Triumph of Decomposition”. En: Parnassus, 4, 4, Nueva York, pp. 4-9+39.

The Societé Anonyme. Modernism for America (2006): Los Ángeles, Museo Hammer-UCLA.

Umland, Anne (ed.) (2008): Joan Miró. Painting and Anti-Painting 1927-1927, Nueva York, Museo de Arte Moderno.

Weisberg, Ruth (1991): “Art Journal at Fifty”. En: Art Journal, 50, 4, Nueva York, p. 7.

Wellman, Rita (1934): "Pioneers and contemporaries". En: Parnassus, 6, 1, Nueva York, pp. 11-14+30.

Zlotsky, Deborah, (1986): "Pleasant madness in Hartford: the first Surrealist exhibition in America". En: Arts Magazine, 60, Nueva York, pp. 55-61.

Fecha de recepción: 23-I-2015

Fecha de aceptación: 17-VI-2015 